\title{
Research on Credit Evaluation System C2C E-commerce Sellers
}

\author{
Zhidan Zhou, Xuekun Liu, Mingli Hou \\ Institute of Modern Logisticsr University of Zhejiang Wanli, Zhejiang Province, China \\ zhouzhd@aliyun.com, 545992443@qq.com
}

\begin{abstract}
C2C e-commerce credit evaluation issues related to credit people online transactions. Articles from the system score and score two modules buyer, seller built $\mathrm{C} 2 \mathrm{C}$ e-commerce credit evaluation index system in the amount of the transaction, current credit buyer, the seller of credit history, the quality of goods, the authenticity of the information, services, prices of key indicators. Through the "T-kill baby" and "Bei Sidi" the two online sellers empirical analysis, mobilize the enthusiasm of the user evaluation, objectively and fairly reflect the transactions and improve credit score sellers to curb unfair evaluation system for new and sellers.

Index Terms - C2C e-commerce, credit evaluation, indicator system
\end{abstract}

\section{Introduction}

In the face of the development of economic globalization, e-commerce will become an important form of economic and trade activities which has a significant impact on the whole social economic life. By the end of June 2013, 591 million Internet users in China, the online trading scale in 2012 amounted to 1.2594 trillion Yuan, annual growth of $66.5 \%$, over the past five years China's online shopping deals to keep high-speed growth, more than 10 times. Online shopping in the rapid development at the same time also brought related issues, represented by taobao.C2C e-commerce credit problems have more and more aroused people's concern, people concern about trade credit when online shopping is one of the major problems of netizens believe that online trading is not safe. In $\mathrm{C} 2 \mathrm{C}$ electronic commerce such as malicious evaluation, through some form of rapid access to credit score, false brush credibility as well as the problems such as deterioration of relations between the seller and the buyer, reflects the $\mathrm{C} 2 \mathrm{C}$ e-commerce credit evaluation system needs to be improved and perfected.

\section{Review of the Literature}

$\mathrm{C} 2 \mathrm{C}$ e-commerce credit evaluation system refers to the buyers and sellers occur on $\mathrm{C} 2 \mathrm{C}$ trading platform to give a method of peer assessment system. Dellarocas on eBay after credit system of online feedback mechanism analysis, proposed only consider the most recent user interaction behavior and ignore the previous behavior earlier OnlyLast reputation model[1]. Yamamoto using the method of multiple Agent for negative or positive reputation effect are analyzed in the process of buyers and sellers trading[2]. Jiam, Yallg sellers can be divided into different types, such as classification is based on the propensity of cheating, construct the operation mechanism of the reputation evaluation mechanism[3]. Josang with cut increase in recent trading evaluation index weight, build Beta reputation evaluation system[4]. Empirical research the seller credit evaluation shows that good reputation evaluation of $\mathrm{C} 2 \mathrm{C}$ online trading can have very good promotion effect, Wan etc. The study found that the sales revenue is reduced in some cases due to the increase in credit rating value caused[5]. Jin found bad review and there is no significant negative correlation relationship between clinch a deal the price[6]. And put forward such as Miller with money reward incentive mechanism, to make up for evaluation by the absence of direct resulting in a loss of reputation system availability and reliability of the[7]. Gutowska think existing single factor concentration method of distributed reputation system will "focus on a problem", and Histos/Spora's research on some problems still has not been taken into account, such as trade value, the credibility of the length of the rating or the referee's credibility [8].

LeiPeiLi on taobao, eBay and other e-commerce sites using "all the assessment points together" and "business credit value separation" mode is analyzed[9]. Piao ChunHui think of $\mathrm{C} 2 \mathrm{C}$ e-commerce credit evaluation can reflect the status of the user's credit and reference for other users to make trading decisions and form system[10]. Yang Deli and Song Guangxing of online reputation management systems in the design of the authenticity of the credit rating of rationality and problems are discussed, and discusses the credibility of assembly methods and credibility evaluation model[11]. Zhu Yanchun points out the deficiencies of the existing trust models, build a trust model based on reliability ratings[12]. Song Guangxing, butyl cloth with soft nap of C2C e-commerce from the perspective of game activities such as buyers and sellers in the selection strategy is analyzed and the research, stressed the importance of credit evaluation management system design perfect [13].

From what has been discussed above, the existing evaluation system of $\mathrm{C} 2 \mathrm{C}$ e-commerce online transactions to a certain extent, ease the credit crisis, increased the traders online trading information, promote the $\mathrm{C} 2 \mathrm{C}$ online trading. But the $\mathrm{C} 2 \mathrm{C}$ e-commerce sites (such as taobao, ebay, etc.) adopted by the seller's lack of credit evaluation system index system of perfect and reasonable criteria, only the simple accumulation of credit evaluation algorithm which can produce the rights of buyers and sellers with unequal power, evaluate the subjectivity of the strong, evaluation factors involved is relatively single, evaluation system of old and new sellers caused unfair, evaluation of the authenticity of the 
suspect, credit evaluation algorithm and evaluation of user credit without contact. Therefore to establish a set of effective seller, credit evaluation system for $\mathrm{C} 2 \mathrm{C}$ e-commerce sites is particularly important.

\section{Research Methods and Data Sources}

\section{A. The research methods}

i) The correlation coefficient.

Correlation refers to the phenomenon exists a connection between the quantitative relation is not strictly interdependence. It is measured both statistic correlation is significant. The calculation method for:

$$
r=\frac{n \sum x y-\sum x \cdot \sum y}{\sqrt{n \sum x^{2}-\left(\sum x\right)^{2}} \cdot \sqrt{n \sum y^{2}-\left(\sum y\right)^{2}}}
$$

Type of correlation coefficient, and two variables respectively. There is a range of numerical, namely- $1 \leq r \leq 1,0.5<|r| \leq 0.8$ is significant correlation, $0.8<|r| \leq 1$ is highly relevant.

ii) Hypothesis test.

Hypothesis testing from the original hypothesis $H_{0}$ and alternative hypothesis $H_{1}$ are proposed according to the topic righteousness, such as $H_{0}: \rho=0, H_{1}: \rho \neq 0$, assuming that the premise of the null hypothesis is correct, to determine the test statistics estimate and calculate the statistics; Specified significance level $\alpha$ (usually take $\alpha=0.05$ or $\alpha=0.01$ ); Determine the critical value, calculate the value of the test statistics and compared with the critical value, judgment and so on several steps. Calculation method for: Might as well use $\mathrm{t}$ test, $t=\frac{|r| \cdot \sqrt{n-2}}{\sqrt{1-r^{2}}}$, when the $t=\geq t_{\frac{\alpha}{2}}, H_{0}$ rejected; When $t=<t_{\frac{\alpha}{2}}, H_{0}$ accept.

\section{B. Data Sources}

Buyers in the data recording current credit score, given the $\mathrm{C} 2 \mathrm{C}$ network transactions(for example Taobao)After several years of development has become larger, so the buyer based on current credit scores Taobao buyers based on credit history. History of the seller's credit score ratio data feedback from buyers historical correlation data on the evaluation of the importance of credit from the questionnaire.

\section{Building C2C E-Commerce Vendor Credit Evaluation System}

\section{A. Indicators selected}

For $\mathrm{C} 2 \mathrm{C}$ e-commerce site in the presence of the seller credit evaluation system issues, and the importance of the findings of the credit evaluation (see Table1), select the transaction amount, the current credit buyer, seller recent trading frequency and the specific buyer rating factor (including the quality of goods, the authenticity of the information, services, prices) as an evaluation index (see Figure 1).
Which, when the system is to determine the rating module transaction, the credit system is based on the amount of the transaction, the buyer and seller current credit score credit score historical record value ratio of the three, with their respective weights, the weighted average is calculated system score; buyer ratings module after the buyer receiving the buyer according to the specific circumstances of the transaction, the quality of goods, information authenticity, service, price four factors to evaluate satisfaction scores derived accordingly, the system combines the respective weights, calculated weighted average number of the buyer score.

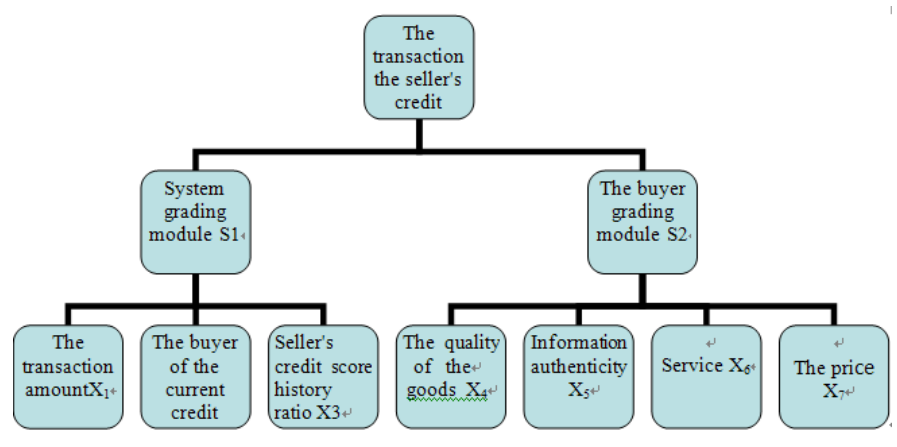

Fig 1 credit score module tree diagram

The difference between system modules and buyer rating score module are: first, different time score generated. Once the transaction is the former, the system had generated score, which must make the evaluation after receipt of goods, the buyer can generate scores buyers. Second, the score values of different nature. The former is the objective value of each factor score. Once the transaction is finished, record values determines the scores, while the latter is the subjective value of each factor score, there are some uncertainties.

\section{B. Determining the weights}

In determining the weight of the transaction amount, the transaction amount will range distinction 1-50, 50-60, 200$500,500-1000$, 5000-10000 yuan. Given C2C transactions rarely occur more than 1 yuan and 10,000 yuan of goods, it would not be considered. And that those rights were given 0.1 , $0.2,0.4,0.6,0.8,1.0$ weight range.

Purchaser current credit score based on buyer historical credit basis to Taobao for example from a heart begins to 5 red crown a total of 20 , the right to a heart weight of 0.05 , followed by a sliding scale 0.05 until right 5 red crown heavy 1.0 so far. The ratio of the seller's credit score history is the history of the seller's feedback, the weights by favorable rate for each additional $10 \%$ weight increase of 0.1 .

Buyer rating module, the quality of goods, including goods is genuine, there is flawless or worn, the packaging is intact and so on. Including a description of the authenticity of the information provided by the seller of goods are consistent sellers trading process the information provided is true and so on.

Communication services, including how the seller attitude towards solving the issues raised whether the buyer in place, 
how the speed of delivery, whether or return. The price includes the price and value of the goods is consistent with the online price match if, and how cost-effective and so on. To determine the quality of the goods, the authenticity of the information, services, and the right to re- price, we did a related investigation, the results are as follows (see Table 1).

TABLE I The importance of credit evaluation survey

\begin{tabular}{|c|c|c|c|c|c|}
\hline N\&P & A & B & C & D & E \\
\hline Q & 95 & 21 & 17 & 4 & 0 \\
\hline I & 20 & 77 & 33 & 7 & 0 \\
\hline S & 15 & 60 & 42 & 9 & 2 \\
\hline P & 36 & 83 & 12 & 6 & 0 \\
\hline
\end{tabular}

Remark: product quality: Q, information authenticity: I, Serice: S, Price: P; veryimportant: A, importan: B, general: C, unimportant: D, very unimportant: $\mathrm{E}$.

Now very important score to 10 points, an important set eight points, usually set to 6 points, unimportant to 4 points, 2 points are very important set of answers to choose five numbers and calculated the correlation coefficient scores $=$ 0.844 , is highly correlated. Meanwhile hypothesis test $t=2.73$

$>t_{\frac{\alpha}{2}}=2.571$ (take $\alpha=0.05$ ), that sample correlation

coefficients are significant, indicating the existence of a linear relationship (see research methods and data sources) to select between the number and the score.

Quality of goods, the authenticity of the information, services, prices of these four indicators scores were classified as "very good, good, fair, poor, very poor," five, corresponding to a score of " $1.0,0.8,0.6,0.4,0.2$ ".

Comprehensive quality of goods available to a weight of
1.0 , the authenticity of the information, services, weights are 0.8 right price.

\section{Vendor credit score}

In the credit evaluation process constructed, the transaction is established, the system automatically according to the current transaction amount, the current buyer credit, the current seller history credit rating score given weight, and calculate the mean, that is, $\mathrm{S}_{1}=\frac{X_{1}+X_{2}+X_{3}}{3}$ this is the objective score.

After the completion of the transaction, the buyer based on the quality of goods, the authenticity of the information, services, prices four indicators give their subjective ratings. Buyer Ratings Module

$$
\mathrm{S}_{2}=\frac{X_{4} \times W_{4}+X_{5} \times W_{5}+X_{6} \times W_{6}+X_{7} \times W_{7}}{4}
$$

The final score for the system vendor credit score and buyer product ratings $\mathrm{S}=\mathrm{S}_{1} \times \mathrm{S}_{2}$.

\section{C2C e-commerce vendor credit evaluation index system}

$\mathrm{C} 2 \mathrm{C}$ e-commerce vendor credit evaluation system by the level indicators and secondary indicators, of which include system-level indicators and the Purchaser score score module module S1 S2, S1 is divided into lower-level indicators of the transaction amount X1, X2 buyer current credit score Vendor history and three secondary indicators such as credit scoring ratio $\mathrm{X} 3, \mathrm{~S} 2$ level indicators corresponding commodity quality $\mathrm{X} 4$, information authenticity $\mathrm{X} 5$, service $\mathrm{X} 6, \mathrm{X} 7$ price of four secondary indicators ( see Table 2 ).

TABLE 2 C2C Electronic commerce the seller' credit evaluation index system

\begin{tabular}{|c|c|c|c|c|c|}
\hline $\begin{array}{c}\text { Level } \\
\text { indicators }\end{array}$ & $\begin{array}{l}\text { secondary } \\
\text { indicators }\end{array}$ & Indicator description & Grade index evaluation & Index weight & $\begin{array}{c}\text { Score } \\
\text { interval }\end{array}$ \\
\hline \multirow{3}{*}{$\begin{array}{l}\text { System } \\
\text { rating }\end{array}$} & $\begin{array}{l}\text { transaction } \\
\text { amount }_{1}\end{array}$ & $\begin{array}{c}\text { transaction in the number of buyers to } \\
\text { purchase goods to pay amount }\end{array}$ & $\begin{array}{c}1-50,50-200,200-500,500- \\
1000,1000-5000,500010000\end{array}$ & $0.1,0.2,0.4,0.6,0.8,1.0$ & {$[0.1,1]$} \\
\hline & $\begin{array}{l}\text { buyer credit at } \\
\text { present } \mathrm{X}_{2}\end{array}$ & buyer's current electronic credit score & $\begin{array}{l}\text { Use taobao now heart rating } \\
\text { from } 1 \text { to } 5 \text { red crown level } 20\end{array}$ & $\begin{array}{l}\text { initial level } 1 \text { heart of } 0.05 \\
\text { to } 0.05 \text { per level increases, } \\
\text { to the top } 51 \text { red crown }\end{array}$ & {$[0.05,1]$} \\
\hline & $\begin{array}{c}\text { Seller's credit } \\
\text { score history } \mathrm{X}_{3}\end{array}$ & Seller's historical transaction rate & $\begin{array}{c}0-10 \%, 10-20 \%, \ldots \ldots, 90 \%- \\
100 \%\end{array}$ & $0.1,0.2, \ldots \ldots, 1.0$ & {$[0,1]$} \\
\hline \multirow{4}{*}{$\begin{array}{l}\text { Buyer } \\
\text { Ratings }\end{array}$} & $\begin{array}{l}\text { The quality of } \\
\text { the goods } \mathrm{X}_{4}\end{array}$ & $\begin{array}{l}\text { Commodity quality, presence of defects or } \\
\text { wear, the packing }\end{array}$ & $\begin{array}{c}\text { Very good-1,good } 0.8,0.6 \text { in } \\
\text { general,poor- } 0.4 \text {,very poor }-0.2\end{array}$ & 1.0 & $\begin{array}{l}\{0.2,0.4,0 \\
6,0.8,1.0\} \\
\end{array}$ \\
\hline & $\begin{array}{l}\text { Information } \\
\text { authenticityX }\end{array}$ & $\begin{array}{l}\text { Product description consistent with the } \\
\text { seller, the seller provides transaction } \\
\text { information is true }\end{array}$ & $\begin{array}{l}\text { Very good-1,good- } 0.8,0.6 \text { in } \\
\text { general,poor-0.4,very poor- } 0.2\end{array}$ & 0.8 & $\begin{array}{l}\{0.2,0.4,0 \\
6,0.8,1.0\}\end{array}$ \\
\hline & Service $\mathrm{X}_{6}$ & $\begin{array}{l}\text { Attitude of the seller, including transaction } \\
\text {-prd after completion of the transaction }\end{array}$ & $\begin{array}{c}\text { Very good- } 1, \text { good- } 0.8,0.6 \text { in } \\
\text { general,poor- } 0.4 \text {, very poor- } 0.2\end{array}$ & 0.8 & $\begin{array}{l}\{0.2,0.4,0 \\
6,0.8,1.0\}\end{array}$ \\
\hline & Price $\mathrm{X}_{7}$ & $\begin{array}{l}\text { How cost of goods, whether in line with the } \\
\text { value in use, is consistent with the market }\end{array}$ & $\begin{array}{c}\text { Very good-1,good- } 0.8,0.6 \text { in } \\
\text { general,poor- } 0.4 \text {,very poor- } 0.2\end{array}$ & 0.8 & $\begin{array}{l}\{0.2,0.4,0 \\
6,0.8,1.0\}\end{array}$ \\
\hline
\end{tabular}

\section{Empirical Analysis}

Now with"T-kill baby" and " Bei Sidi " two online sellers, for example, were to purchase goods price, buyer credit, the seller credit history scores, quality of goods, information authenticity, service and price variables data modeling and tracking, and record online shopping score data for comparison. Since the system is not really set up, so the system module based on standard rating score and recorded by hand .

Given the rating module permutations calculated after scores level too, only the final score grading buyer rating module for the five files that are" good, good, fair, poor, very poor," corresponding to the quality of goods, information on authenticity, service and price evaluation proceeds are "very good, good, fair , poor, very poor," the score. According to correspondence with the respective weights score calculated 
buyer rating module integrated the lowest score of 0.17 and a maximum of 0.85 , a total of five files into the group at 0.17 .

\section{A. Item price variable}

Crown purchasers with a red "T-kill baby" shop 20.4 yuan natural pearl earrings, 168 yuan jade rings, 480 yuan and 750 yuan pearl necklace Myanmar jade pendant, for example, is divided into A, B, C, D four groups, calculate the final score ( in contrast to other constant volume defaults to the maximum, the same below ) .

$\mathrm{A}=\frac{0.1+1.0+1.0}{3} \times \frac{1.0 \cdot 1.0+1.0 \cdot 0.8+1.0 \cdot 0.8+1.0 \cdot 0.8}{4}=0.7 \times$
$0.85=0.595 \quad \mathrm{~B}=\frac{0.2+1.0+1.0}{3} \times 0.85=0.623$
$\mathrm{C}=\frac{0.4+1.0+1.0}{3} \times 0.85=0.68 \quad \mathrm{D}=\frac{0.6+1.0+1.0}{3} \times 0.85=0.737$

Thus, according to the increment in commodity prices, in other factors constant seller's credit will increase, eliminate the large transactions and micro credit ultimately increase the value of the transaction proceeds the same phenomenon.

\section{B. The buyer as a variable credit}

Level with a heart level, a star level, a yellow crown level and a red crown level of buyers to buy 480 yuan pearl necklace, for example, is divided into A,B,C,D four groups calculate their final scores were $0.354,0.425,0.496,0.567$. Thus, according to the buyer 's own credit increments, in other factors constant seller's credit will increase, eliminate the high degree of buyers with low credit credit credit buyers to evaluate the performance of the seller proceeds the same phenomenon.

\section{To the seller of credit history as a variable ratio}

To "T-kill baby" shop and "Bei Sidi" shop in [50-200] range of goods, for example, according to two different historical shop favorable rate into A, B groups, including "Tkill baby "shop for the old shop, has accumulated a certain amount of credits, "Bei Sidi" shop for a new open shop, credit score less, but" T-kill baby" shop because the shop a long time, unavoidable circumstances appear favorable rate of less than $100 \%, 93 \%$ now praise. And "Bei Sidi" shop currently still favorable rate of $100 \%$, in other conditions remain unchanged score of $0.6035,0.6233$ respectively.

Under the new shop when it opened in view of the absolute majority of credit as good as the old shop, but the proportion of its favorable rate greater than the old shop phenomenon, adding this value to make a new shop in other conditions the same situation with the old shop get more credit points add up shop in order to catch up with old, avoiding the existing evaluation system for new and old shop unfair competition.

\section{To the authenticity of the information variables}

To "T-kill baby" shop and "Bei Sidi" shop in [200-500] The same product range as an example, where buyers think highly of the former information authenticity, the latter general information authenticity, points as a, B groups, in other conditions remain unchanged were scored as $0.68,0.616$. Thus, according to the information of the authenticity of the degree increments, in other factors constant seller's credit score will increase.

\section{E. As a variable cost price}

To "T-kill baby" shop and "Bei Sidi" shop in [200-500] The same product range as an example, where buyers think the price of the former high cost, which is generally cost-effective price, divided into A, B groups, under other conditions remain unchanged score $0.68,0.616$ respectively. Thus, based on the incremental cost of goods and their prices, in other factors constant seller's credit score will increase.

In addition, the buyer score four modules variable longitudinal comparison, the same amount found in the difference between 1.0 and 0.6 , the score gap between the quality of goods is 0.08 , the other three score gap is 0.064 , which illustrate the quality of goods to the seller credit scores affect more than the other three, in line with the survey results.

\section{Acknowledgment}

The research work was supported by the Zhejiang social sciences key research base (the Modern Port Service Industry and Cultural Research center of the Key Research Base of Philosophy and Social Sciences of Zhejiang Province); Zhejiang Province Key Discipline (Service Management and Engineering).

\section{References}

[1] Dellarocas C. Efficiency and Robustness of EBay-like Online Feedback Mechanisms in Environments with Moral Hazard. Working Paper Cambridge: Sloan School of Management. pp, 43 45; 2011(11).

[2] Yamamot H. Modeling Reputation Management. Computational \& Mathe-matical Organization Theory. pp, 165 178; 2004(10).

[3] Jian Yang, Xiaorui Hu, Han Zhang. Effects of a reputation feedback system on An online consumer-to-consumerauction market. Decision Supports Systems.pp, 93 105; 2007(44).

[4] Josang A, Ismail R. The Beta Reputation System. http://www.unikno/ people/josang/ papers/JI2002-Bled.pdf.2010.

[5] Wan W, TeoH H. An examination of auction price determinants on eBay. http: //is2lse.ac.uk/asp/aspecis /20010118.pdf.2010.

[6] Jin G. Blind trust online: Experimental evidence from baseball cards. http://www.vanderbiltedu /Econ/sem-papers/Jin.pdf.2009.

[7] Miller N, Resnick P, Zeckhauser R. Eliciting honest feedback in electronic markets. http://www.ksgharvardedu/nhm/paper_files/elicit. pdf. 2009.

[8] Gutowska A, Sloane A, Buckley K A. Buckley. On Desideratum for B2C E-Commerce Reputation Systems. Journal of computer science and technology, 24(5):820 832 Sept.2009.

[9] Lei Peili and Zhan jia, C2C e-commerce credit evaluation system problems and Algorithm, Modern Business, pp.52 53; 2009(12).

[10] Pu Chunhui, An Jing and Fang Meiqi, Research on Credit Evaluation Model and Algorithm for C2C E-commerce Website Journal of Information, pp.105 107; 2007(8).

[11] Song Xingguang and Yang Deli, Some Issues in Electronic Commerce Online reputation management system design. Systems Engineering. 22(9), pp.5 9; 2004.

[12] Ma Xiaohong, A Comparative Study of C2C online store credit evaluation system, Journal of Changchun University of Science and Technology. 4(7), pp.176 179; 2009.

[13] Tian Jian and Liang Guohong, Comparative Research on Trust models in $\mathrm{C} 2 \mathrm{C}$ online Auctions, An Academic Edition of ManaMaga. Pp.31 39; 2011(6). 